\title{
TERATOCARCINOSARCOMA OF THE NASAL AND MAXILLARY SINUS MASS- A RARE CASE
}

\author{
Snehpreet Kaur Sandhu1, Romi Kant Grover2, Raja P. S. Banipal', Harkirat Kaur ${ }^{4}$
}

1 Resident, Department of Radiation Oncology, Guru Gobind Singh Medical College and Hospital, Faridkot, Punjab, India. ${ }^{2}$ Assistant Professor, Department of Radiation Oncology, Guru Gobind Singh Medical College and Hospital, Faridkot, Punjab, India. 3 Professor, Department of Radiation Oncology, Guru Gobind Singh Medical College and Hospital, Faridkot, Punjab, India. ${ }_{4}^{4}$ Resident, Department of Radiation Oncology, Guru Gobind Singh Medical College and Hospital, Faridkot, Punjab, India.

HOW TO CITE THIS ARTICLE: Sandhu SK, Grover RK, Banipal RPS, et al. Teratocarcinosarcoma of the nasal and maxillary sinus mass- a rare case. J. Evolution Med. Dent. Sci. 2019;8(11):821-823, DOI: 10.14260/jemds/2019/182

\section{PRESENTATION OF CASE}

A 42-yr. old man presented with chief complaints of nasal blockage, nasal bleeding and later on pain in the eyes and headache and progress to nasal mass within period of 3 months. Routine haematological and biochemical investigations were done, which were normal at the time of presentation. Nasal endoscopy was done which showed nasal mass which bleeds on touch. A computed tomography (CT) scan face and neck revealed an inhomogenously enhancing soft tissue density lesion measuring $5.7^{*} 3.3 * 3.9 \mathrm{~cm}$ involving left maxillary sinus extending to left ethmoid sinus, left nasal cavity reaching up to posterior choana abutting the nasal septum (Figure 1).

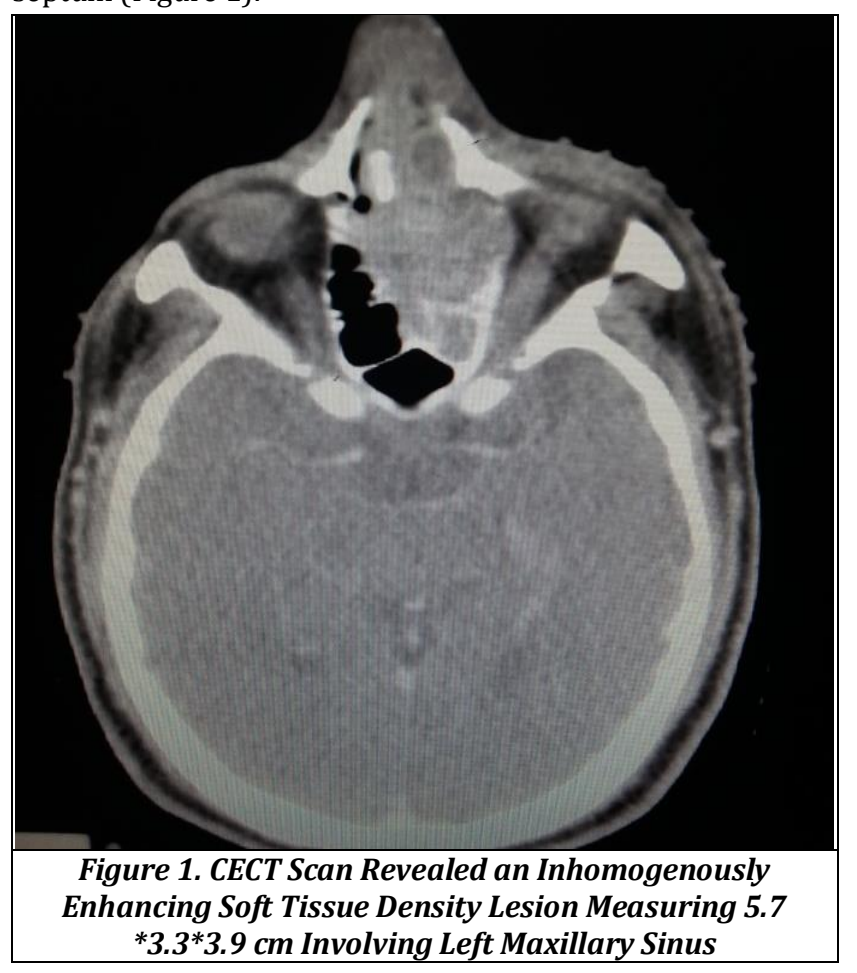

'Financial or Other Competing Interest': None. Submission 21-11-2017, Peer Review 28-02-2019,

Acceptance 06-03-2019, Published 18-03-2019.

Corresponding Author:

Romi Kant Grover,

Assistant Professor

Department of Radiation Oncology,

Guru Gobind Singh Medical College and Hospital,

Faridkot, Punjab,

India.

E-mail:drgrover66@yahoo.in

DOI: $10.14260 /$ jemds $/ 2019 / 182$

\section{(c) (i) $(9)$}

\section{DIFFERENTIAL DIAGNOSIS}

\section{Epithelial Tumours}

1. Squamous cell carcinoma.

2. Transitional cell carcinoma.

3. Adenocarcinoma.

4. Adenoid cystic carcinoma

5. Melanoma.

6. Olfactory neuroblastoma.

\section{Non-Epithelial Tumours}

1. Soft tissue sarcoma.

2. Rhabdomyosarcoma.

3. Liposarcoma.

4. Chondrosarcoma.

5. Osteosarcoma.

\section{Lymphoreticular Tumours}

1. Plasmacytoma.

2. Giant cell tumour.

\section{PATHOLOGICAL DISCUSSION}

Sinonasal teratocarcinosarcoma (SNTCS) is a very rare and aggressive neoplasm of malignant potential histologically characterized by the combination of one or many components of epithelial and mesenchymal elements.(1) It is characterized by the histologic combination of malignant teratoma and carcinosarcoma with a triphasic growth pattern including epithelial, mesenchymal and primitive neuroectodermal components(2), and it mainly occurs in the nasal cavity and paranasal sinuses, although tumours occurring at other locations like nasopharynx and oral cavity have also been described. $(3,4,5)$

These tumours has an insidious onset and patient become symptomatic after the tumour invades the surrounding tissues in advanced stages making the overall prognosis poor.(6) The rare presentation of these tumours and varied combination histopathological features, with its infrequency and the complex phenotypic compositions the lesions are often misdiagnosed, leading to difficulties in management.(7) Here we report a case of locally advanced nasal teratocarcinosarcoma managed by chemoradiotherapy.

\section{Histopathology}

Endoscopic excision biopsy was done and the dark brown soft tissue pieces measuring $4 * 3.5 * 1.5 \mathrm{~cm}$ were sent for histological examination. All blocked in 3217A-C/16. The viable fragments show a biphasic tumour composed of epithelial and mesenchymal components. The epithelial component is composed of small round to oval cells and scant cytoplasm arranged in sheets. Some areas of epithelial 
component show Homer-Wright and Flexner Wintersteiner rosettes while some areas show primitive neuroectodermal component with gland formation.

The intervening mesenchyme is composed of plump to spindle shaped cells. Areas of epithelium to mesenchymal transition are also seen. Further on immunohistochemistry, tumour showed CK, Chromogranin A, NSE in epithelial component; CD99 focally positive in epithelial component; Vimentin diffusely positive in stromal and focally positive in epithelial component; Ki67 focally high in epithelial component; Myf4 was negative.
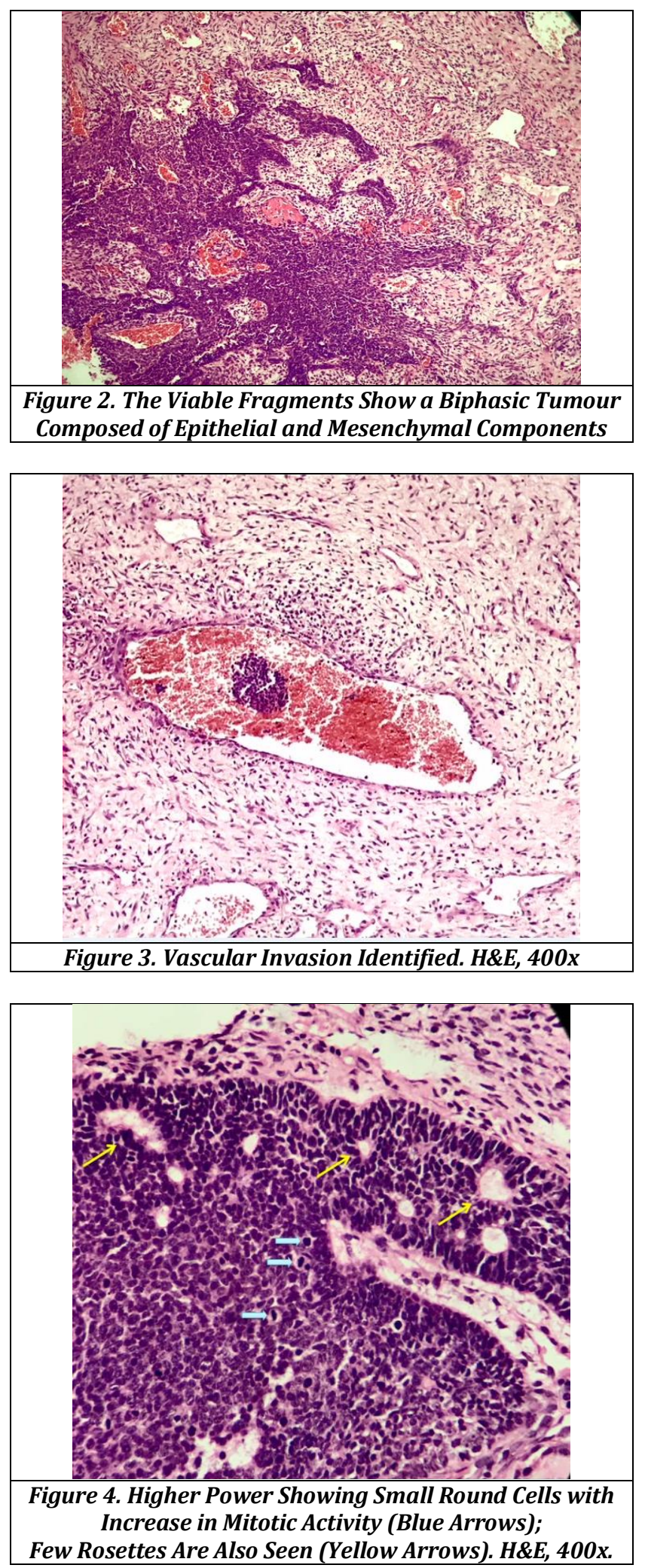

Thus, a histopathological and immunohistochemical diagnosis of teratocarcinosarcoma was made. Blocks were reviewed showing features consistent with the diagnosis.

\section{DISCUSSION OF MANAGEMENT}

Patient underwent excision biopsy of nasal mass via transnasal approach. In view of residual disease, patient was managed with Intensity Modulated Radiotherapy with 6 MV energy on linear accelerator and total radiotherapy dose of 68 Gray (Gy) to Gross tumour volume (Which is gross residual disease post operation), 66 Gy to Clinical Target Volume (To include micro metastasis), 64 Gy to Planning Target Volume and 58 Gy to neck nodes in 33\# over 6.3 weeks along with concomitant systemic chemotherapy with injection Cisplatin- $40 \mathrm{mg} / \mathrm{m}^{2}$ weekly. Common complications of concurrent chemoradiation were Grade II to Grade III mucositis leading to swallowing dysfunctions which were managed with supportive care.

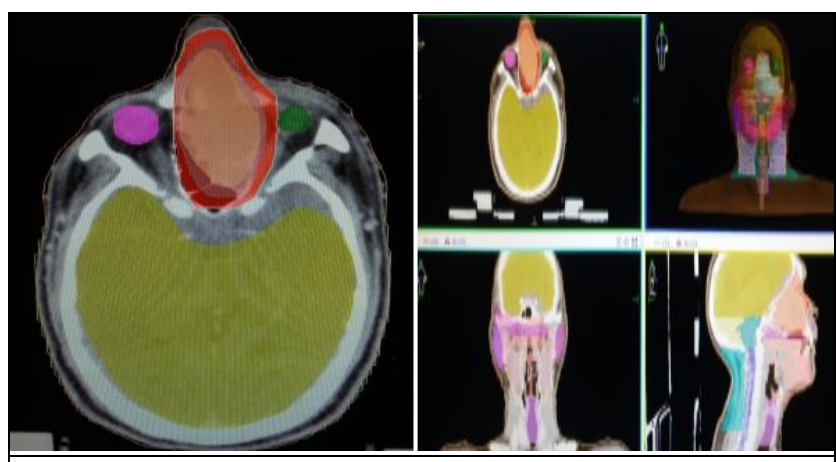

Figure 5. Showing GTV-Cream Colour, CTV-Brown, PTV-Red

Follow up CECT neck on $6^{\text {th }}$ April 2017 shows soft tissue thickening measuring $1.2 * 1.7 * 1.9 \mathrm{~cm}$ involving the left maxillary sinus extending to left ethmoid sinus, left nasal cavity reaching up to posterior choana suggestive of post treatment changes. Now patient is on follow up from last 2 years with no evidence of recurrence.
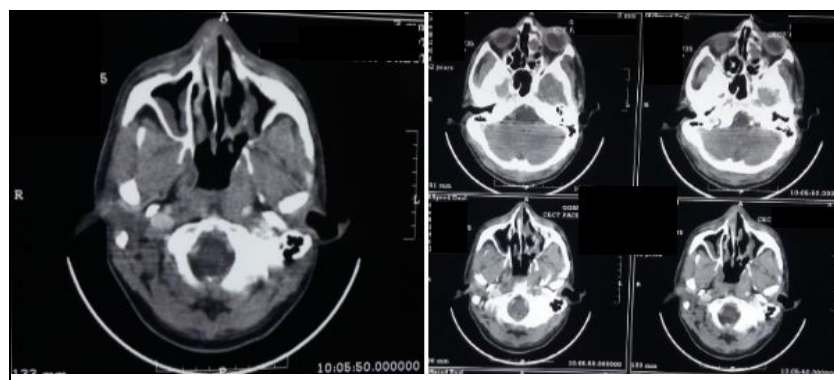

Figure 6. Post-Treatment CECT Neck Showing Reduction in Mass

\section{FINAL DIAGNOSIS}

Teratocarcinosarcoma

Microscopically sinonasal teratocarcinosarcoma consists of primitive neuroepithelial elements with more than one malignant epithelial and mesenchymal components probably originating from stem or pluripotent progenitor cell with multidirectional differentiation. $(8,9)$ Cervical node metastasis are seen in $17 \%$ and no elective neck dissection is indicated.(6) The term teratocarcinosarcoma was coined in 1984 by Heffner and Hyams in view of its complex histopathological pattern. Histologically, it is different from 
true carcinosarcoma which consists of a single malignant mesenchymal component, whereas SNTCS has one or many epithelial and mesenchymal components (both benign and malignant).(1) Despite several studies, the histogenesis of this tumour remains controversial. Common clinical features include nasal obstruction and epistaxis with the average duration of symptoms being reported at 3.5 months.(10) Incidence is seven times higher in males.(11,12) Currently, 97 cases have been reported in world literature.(6) Heffner and Hyams justified the term "teratocarcinosarcoma" in his case series on 20 patients ranged from 18 to 79 yrs. with median age of 60 yrs., the histological features differed from gonadal germ cell neoplasms. They suggested aggressive multimodality method of treatment including surgery, radiotherapy and chemotherapy, as only $40 \%$ of the patients lived more than 3 years and average follow up was 6.1 yrs.(13)

Multiple modality treatment including surgery, chemotherapy and radiation therapy is the treatment of choice. According to Budrukkar et al, combination of radiotherapy and surgery offer best five-year survival rate of $50 \%$ followed by surgical treatment.

Local recurrence after surgery was seen in 30 to $43 \%$, hence adjuvant treatment is recommended in the form of radiation and chemotherapy. $(10,14)$ As the tumour is highly aggressive and rare, no adequate radiotherapy doses are described and individualization of therapy should be considered.(8,9) The complex tumour shape and close proximity to critical structures has made 3D CRT (3dimensional conformal radiotherapy) and IMRT (Intensity Modulated Radiotherapy) better in delivering higher radiation doses to the target volumes. (6)

\section{REFERENCES}

[1] Mondal SK, Mandal PK, Guha A, et al. Sinonasal teratocarcinosarcoma of the ethmoid and paranasal sinus: a rare neoplasm. J Res Med Sci 2012;17(6):5757.

[2] Fernandez PL, Cardesa A, Alos L, et al. Sinonasal teratocarcinosarcoma: an unusual neoplasm. Pathol Res Pract 1995;191(2):166-71, discussion 172-3.

[3] Carrizo F, Pineda-Daboin K, Neto AG, et al. Pharyngeal teratocarcinosarcoma: review of the literature and report of two cases. Ann Diagn Pathol 2006;10(6):33942.
[4] Rotenberg B, El-Hakim H, Lodha B, et al. Nasopharyngeal teratocarcinosarcoma. Int J Pediatr Otolrhinolaryngol 2002;62(2):159-64.

[5] Crazzolara R, Puelacher W, Ninkovic $M$, et al. Teratocarcinosarcoma of the oral cavity. Pediatr Blood Cancer 2004;43(6):687-91.

[6] Budrukkar A, Agarwal JP, Kane S, et al. Management and clinical outcome of sinonasal teratocarcinosarcoma: single institution experience. J Laryngol Otol 2010;124(7):739-43.

[7] Naik SM, Nanjundappa, Halkud R, et al. Sinonasal teratocarcinosarcoma: a rare clinical entity managed by medial maxillectomy and adjuvant chemoradiation. Clin Rhinol An Int J 2012;5(3):118-22.

[8] Terasaka S, Medary MB, Whiting DM, et al. Prolonged survival in a patient with sinonasal teratocarcinosarcoma with cranial extension. Case report. J Neurosurg 1998;88(4):753-6.

[9] Batsakis JG, El-Naggar AK, Luna MA. Teratomas of head and neck with emphasis on malignancy. Ann Otol Rhinol Laryngol 1995;104(6):496-500.

[10] Smith SL, Hessel AC, Luna MA, et al. Sinonasal teratocarcinosarcoma of the head and neck: a report of 10 patients treated at a single institution and comparison with reported series. Arch Otolaryngol Head Neck Surg 2008;134(6):592-5.

[11] Lim TCC, Thiagarajan A, Sim CS, et al. Craniospinal dissemination in teratocarcinosarcoma. J Neurosurg 2008;109(2):321-4.

[12] Wei S, Carroll W, Lazenby A, et al. Sinonasal teratocarcinosarcoma: report of a case with review of literature and treatment outcome. Ann Diagn Pathol 2008;12(6):415-25.

[13] Heffner DK, Hyams VJ. Teratocarcinosarcoma (malignant teratoma?) of the nasal cavity and paranasal sinuses a clinicopathologic study of 20 cases. Cancer 1984;53(10):2140-54.

[14] Sharma HS, Abdullah JM, Othman NH, et al. Teratocarcinosarcoma of the nasal cavity and ethmoid. J Laryngol Otol 1998;112(7):682-6. 